\title{
Recruitment, growth and mortality of juvenile corals at Eilat, northern Red Sea
}

\author{
D. Glassom ${ }^{1,2, *}$, N. E. Chadwick ${ }^{1,3}$ \\ ${ }^{1}$ Interuniversity Institute for Marine Science, PO Box 469, Eilat, Israel, and Faculty of Life Sciences, \\ Bar Ilan University, Ramat Gan, Israel \\ ${ }^{2}$ Present address: Oceanographic Research Institute, PO Box 10712, Marine Parade, Durban 4056, South Africa \\ ${ }^{3}$ Present address: Department of Biological Sciences, 101 Rouse Life Science Building, Auburn University, \\ Auburn, Alabama 36849, USA
}

\begin{abstract}
Rates of recruitment, growth and survival during the early life stages of stony corals may strongly impact community structure on tropical reefs, yet sparse information is available on these processes. We assessed juvenile coral dynamics on coral reefs near Eilat, northern Red Sea. Rates of recruitment among stony-coral genera were similar at sites in close proximity $(<200 \mathrm{~m})$, but not at a more distant site $(2 \mathrm{~km})$, which differed in substratum type and reef morphology. We observed 42 to 173 juvenile coral colonies $\mathrm{m}^{-2}$ of reef substratum, a much higher abundance than previously reported from reefs in the Caribbean Sea, but potentially similar to abundance on other Indo-Pacific reefs that are known to have higher coral recruitment than Caribbean reefs. Growth rates of juvenile corals were similar among sites and genera, but varied significantly with season. Juvenile mortality varied significantly among reef sites in some coral genera, and was particularly high for individuals of Stylophora spp., weedy corals that also had high rates of recruitment of juveniles, and thus rapid population turnover. Growth and mortality rates of corals at these sites were within values recorded for other reef locations worldwide. We conclude that on shallow reefs in the northern Red Sea, relative abundances of juvenile coral genera depend mainly on variation in their recruitment patterns, and do not vary significantly with rates of juvenile growth or mortality.
\end{abstract}

KEY WORDS: Scleractinia $\cdot$ Abundance $\cdot$ Population dynamics $\cdot$ Community structure $\cdot$ Diversity Reef $\cdot$ Northern Red Sea

Resale or republication not permitted without written consent of the publisher

\section{INTRODUCTION}

Studies of population ecology have concentrated mainly on organisms with simple life cycles (Roughgarden et al. 1988) or on the adult phases of organisms with complex life cycles, such as benthic marine invertebrates (Grosberg \& Levitan 1992, Eckman 1996). In recent years, increasing attention has been paid to processes of larval dispersal and settlement in marine organisms, but mortality of juveniles after settlement has remained somewhat neglected, despite the acknowledged importance of post-settlement processes in structuring communities (Sammarco 1991). Larval production, dispersal and settlement may gen- erate extensive variation in the population size and community structure of marine benthic invertebrates (Holm 1990, Caley et al. 1996). The importance of single-age cohorts may be evened out over time, diminishing the dependence of long-lived organisms on individual recruitment events (Hughes 1990), but recruitment remains an important factor in the population structure of benthic organisms such as scleractinian corals, especially following disturbances (Miller et al. 2000).

Newly-settled corals are vulnerable to a variety of stressors that larger corals are able to tolerate, and may be killed by disturbances from which adult corals can recover (Bak \& Meesters 1998). Juvenile corals are less 
able to secure or defend space, particularly in areas with high nutrient levels (Birkeland 1977), although this ability varies between species with different lifehistory traits (Tanner et al. 1996). Hence, the relative contributions of recruitment and post-recruitment processes to overall community structure in marine ecosystems remains poorly understood (Caley et al. 1996), but post-settlement mortality is known to be important in determining adult-coral population structure (e.g. Miller et al. 2000).

In order to assess the persistence of populations, the fate of all adults should be followed for a full generation, or the probability of their survival estimated (Connell \& Sousa 1983). Since corals are long-lived and have low mortality rates once large sizes are reached, following the fate of all adults is difficult and estimation of survival is a more feasible option. The probability of persistence of a coral colony changes with time, increasing as the coral becomes older and larger (Tanner et al. 1996). The rate of growth in the first year has an important effect on the ultimate survival of juvenile corals (Birkeland 1977). Scarcity of data on early growth rates has led to underestimates of the age of coral recruits (Harrison \& Wallace 1990).

Rates of recruitment and mortality of newly settled corals are influenced by numerous physical factors ranging from microtopography to geography (Connell et al. 1997). Biological factors such as competition (Branch 1984) and whether recruits are from brooding versus spawning corals (Connell et al. 1997) also influence recruitment rates at a variety of scales. Measurements of population parameters at a wide range of spatial and temporal scales are thus necessary. Concentrating research exclusively at large scales will conceal small-scale patterns of change and heterogeneity (Connell et al. 1997); nonetheless, there are few small-scale ecological studies of juvenile coral dynamics. Data on mortality rates of juvenile corals typically depend on single surveys (Bak \& Engel 1979, Rogers et al. 1984), on surveys repeated at intervals of a year or longer (Tanner et al. 1996, Edmunds 2000, Miller et al. 2000), or on the use of spat settled under laboratory conditions on artificial substrata (Babcock 1985, Sato 1985). Exceptions are the studies of Birkeland (1977), Hughes (1989) and Wittenberg \& Hunte (1992), in which surveys were conducted at intervals ranging from $1 \mathrm{~d}$ to $6 \mathrm{mo}$.

For coral reefs in the Red Sea, as elsewhere, data on juvenile coral dynamics are sparse. Loya (1976a) observed high mortality of recruits of the branching stony coral Stylophora pistillata on artificial substratum at Eilat. Also at Eilat, mortality rates of spat of the massive corals Platygyra lamellina and Favia favus, which were settled on artificial substrata and then placed on the reef. Their mortality rates were: $99.7 \%$ before reaching primary polyp stage was reached, and then $33 \%, 18$ and 19 during the 1st, 2nd and 3rd yr, respectively (Shlesinger \& Loya 1991). High mortality of young individuals was inferred from age structure and individual growth rates in a population of the freeliving coral Fungia granulosa at Eilat (ChadwickFurman et al. 2000), although settlement and recruitment rates were not monitored directly. Juvenile mortality rates varied between species of mushroom corals (Goffredo \& Chadwick-Furman 2001).

Thus, although studies have been conducted on selected species, the dynamics of entire assemblages of coral juveniles on Red Sea reefs remain unknown. We report here on patterns of juvenile coral recruitment, growth and mortality on reefs at Eilat, northern Red Sea, and estimate their respective importance to coral community development at 3 reef sites. We also compare patterns of juvenile recruitment observed here with those recorded in our previous study on artificial substrata at Eilat (Glassom et al. 2004).

\section{MATERIALS AND METHODS}

Site description. We selected 3 reef sites to reflect different levels of coral settlement, based on a previous study (Sites 2, 8 and 9 in Glassom et al. 2004) and the hypothesis that more northerly sites may have lower recruitment, since they are closer to presumed sources of pollution (Fishelson 1973, Loya 1976a, 1990). Of these sites, 2 were adjacent to the Interuniversity Institute for Marine Science (IUI) near Eilat. The northernmost site (IUI North) was located next to the boat pier of the IUI, approximately $200 \mathrm{~m}$ south of the Coral Beach Nature Reserve (CBNR, Fig. 1); the second site (IUI South) was situated about $150 \mathrm{~m}$ south of the IUI North site. The substratum at both sites was predominantly metamorphic beach rock interspersed with coarse sand. The patch reefs in this area were in early stages of development (Loya 1976a) and most of the area available for coral recruitment was metamorphic rock. The third site (Taba) was selected near the border between Egypt and Israel, approximately $2 \mathrm{~km}$ south of the IUI (Fig. 1). At Taba, most of the available recruitment substratum was calcium-carbonate coral skeleton, and the site consisted of well-developed patch reefs interspersed with fine sand. We examined 4 transects at approximately $5 \mathrm{~m}$ depth at each site. At the Taba site, 3 of the 4 transects were located on the vertical sides of coral patch-reefs; the 4 th transect and all transects at the other 2 sites were on predominantly horizontal surfaces. Areas of medium-to-low adult coral cover (10 to $40 \%$ ) were selected for all transects, to minimize the effects of space limitation on coral recruitment. Thus, results presented here represent 
maximum possible values of coral recruitment to reef substratum at these sites in Eilat.

Each transect $(3.0 \times 0.2 \mathrm{~m})$ was marked with a series of plastic plugs permanently fixed in holes made in the substratum. The number of plugs per transect (4 to 10) and the distance between them varied according to the rugosity of the substratum. Flexible wire inserted through a hole in the top of each plug was used to hold a tape-measure securely in place when transects were surveyed. These small, narrow transects, therefore, closely followed the topography of the substratum. The tape-measure served as the center of the transect, which extended $10 \mathrm{~cm}$ on either side of the tape. The distance along the tape-measure as it passed over the center of each plug was recorded to facilitate precise repositioning of transects in subsequent surveys. A long, narrow transect shape was chosen rather than a square one, because the area surveyed was less likely to vary and corals were easier to relocate between samples. All transects were surveyed 3 times (December 2000, April 2001 and August 2001).

Juvenile corals were located by direct examination of the substratum during SCUBA dives, since this is preferable to photographic methods for censusing very small corals (Edmunds et al. 1998). During each sampling period, the substratum was visually scrutinized using a magnifying glass to facilitate the detection of coral recruits as small as $1 \mathrm{~mm}$ diameter. All corals were measured in 3 dimensions where possible (length, width, height); in the case of very small colonies, it was often not possible to measure height. The location of each coral in the transect was also recorded using coordinates (distance along and to the right or left of the tape-measure) for relocation of individual corals during subsequent surveys. All stony corals $<40 \mathrm{~mm}$ diameter ([length + width]/2) were considered to be juveniles (after Bak \& Engels 1979, Rogers et al. 1984, Wittenberg \& Hunte 1992, Chiappone \& Sullivan 1996); however this definition may be inappropriate for some species that attain maturity at very small colony-sizes (Miller et al. 2000). The term juvenile recruits is used throughout the text to designate corals observed on the substratum for the first time (after Harrison \& Wallace 1990) — thereafter, they are called juveniles. The term 'juvenile' may include new recruits, such as when the total number of juvenile corals is referred to.

Morphological characteristics of many coral species become apparent only when colonies are several years old (Hughes et al. 2000). In our separate analysis of adult coral abundances, little resolution was lost by the use of genus rather than species-level classification (Glassom 2002). Genus-level resolution is also known to be adequate for tracking the recovery of coral communities after disturbances (Warwick et al. 1990), and

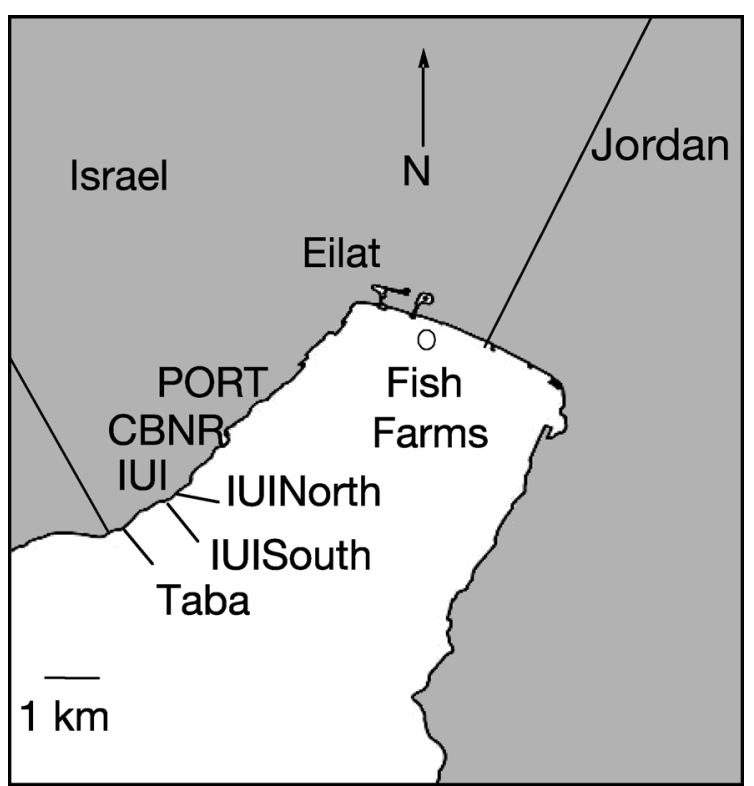

Fig. 1. Coral reef study sites near Eilat. CBNR: Coral Beach Nature Reserve; IUI: Interuniversity Institute for Marine Science. Black lines: 3 reef sites

for monitoring pollution impacts in marine communities (Somerfield \& Clarke 1995). In the present study, corals were identified to genus where possible, using a magnifying glass to closely examine corallite structure. Where genus could not be determined, as for faviid corals at the single-polyp stage, or for very small pocilloporid recruits, juvenile corals were identified to family level. Corals that were not identifiable to family level were recorded as 'others'. Seasonal reproductive patterns of pocilloporid corals were also employed as an additional identifying feature for genera. For example, pocilloporid corals that appeared in April probably belonged to the genus Stylophora, because this is the only genus in the family known to spawn during this month at Eilat (Shlesinger et al. 1998). In some cases, small corals that were not identified when they first appeared were identified during later surveys.

Data were analyzed statistically using Primer Version 5.2 (PRIMER-E) for multivariate statistics, and SAS Version 8 (SAS 1999) for univariate statistics. The ANOSIM (analysis of similarity) conducted in PRIMER, is a non-parametric test of the similarity matrix underlying the classification of samples (Clarke \& Warwick 2001). Survival curves were constructed using the lifetable method of the LifeTest procedure in SAS, based on juveniles followed since the first survey in December 2000. The life-table method derives the survival curves by calculating a 'survivor distribution function' from the raw data, providing an estimate of the probability of survival of individuals of certain age classes 
and conducts statistical comparisons of the curves. The 'vertical' or time-specific life-table, used here, predicts survival based on an imaginary cohort, found by determining the age structure of a sample of a population with overlapping generations (Southwood 1966 [p. 277-311], SAS Institute 1999).

Since age-related data were not available, coral size increments were used to construct the curves, effec-

Table 1. Families and genera of juvenile stony corals observed at 3 reef sites near Eilat in August 2001. Presented are numbers of colonies $\mathrm{m}^{-2}$. Data are mean (SD) no. of colonies $\mathrm{m}^{-2} ; \mathrm{N}=4$ transects per site. Others: not identifiable to family level. An additional genus (Turbinaria) was represented by a single juvenile colony that died before August 2001 and is not included in table

\begin{tabular}{|c|c|c|c|}
\hline Taxon & IUI North & IUI South & Taba \\
\hline Faviidae & $15.00(3.85)^{\mathrm{a}}$ & $16.67(7.07)^{\mathrm{a}}$ & $2.08(3.15)^{\mathrm{a}}$ \\
\hline Favia & 27.08 (16.29) & $19.17(12.36)$ & $1.67(1.93)$ \\
\hline Favites & $20.00(6.80)$ & $30.83(9.08)$ & 4.17 (2.89) \\
\hline Cyphastrea & $10.42(6.58)$ & $12.50(6.46)$ & $5.83(4.19)$ \\
\hline Leptastrea & $8.75(0.83)$ & 31.25 (9.56) & $6.25(3.70)$ \\
\hline Platygyra & $5.83(6.31)$ & $4.58(3.43)$ & $0.42(0.83)$ \\
\hline Goniastrea & $5.00(1.36)$ & $2.50(0.96)$ & $0.83(1.67)$ \\
\hline Echinopora & $0.42(0.83)$ & $0.83(1.67)$ & $1.25(0.83)$ \\
\hline Montastrea & $0.42(0.83)$ & $1.25(1.59)$ & $0.00(0.00)$ \\
\hline \multicolumn{4}{|l|}{ Acroporidae } \\
\hline Acropora & $1.25(1.60)$ & $0.83(0.96)$ & $0.42(0.83)$ \\
\hline Astreopora & $0.00(0.00)$ & $0.42(0.83)$ & $0.42(0.83)$ \\
\hline Montipora & $0.00(0.00)$ & $2.08(2.50)$ & $1.67(1.37$ \\
\hline Pocilloporidae & $3.75(2.85)^{\mathrm{a}}$ & $0.83(1.67)^{\mathrm{a}}$ & $0.42(0.83)^{\mathrm{a}}$ \\
\hline Pocillopora & $0.00(0.00)$ & $1.25(0.83)$ & $0.83(0.97)$ \\
\hline Stylophora & $18.33(10.54)$ & $15.83(10.05)$ & $1.25(1.60)$ \\
\hline \multicolumn{4}{|l|}{ Poritidae } \\
\hline Porites & $2.92(2.10)$ & $4.58(3.70)$ & $2.92(2.85)$ \\
\hline \multicolumn{4}{|l|}{ Siderastreidae } \\
\hline Coscinarea & $4.58(4.59)$ & $2.08(1.60)$ & $0.42(0.83)$ \\
\hline Psammocora & $0.42(0.83)$ & $2.50(2.15)$ & $2.08(3.16)$ \\
\hline \multicolumn{4}{|l|}{ Agariciidae } \\
\hline Pavona & $0.00(0.00)$ & $1.67(1.93)$ & $3.33(3.85)$ \\
\hline \multicolumn{4}{|l|}{ Fungiidae } \\
\hline Fungia & $0.00(0.00)$ & $0.83(1.67)$ & $0.83(1.67)$ \\
\hline \multicolumn{4}{|l|}{ Oculinidae } \\
\hline Galaxea & $0.00(0.00)$ & $0.42(0.83)$ & $0.00(0.00)$ \\
\hline \multicolumn{4}{|l|}{ Mussidae } \\
\hline Acanthastrea & $7.50(4.19)$ & $13.33(3.60)$ & $2.08(1.60)$ \\
\hline Cynarina & $0.42(0.83)$ & $0.42(0.83)$ & $0.42(0.83)$ \\
\hline Lobophyllia & $0.00(0.00)$ & $0.42(0.83)$ & $0.00(0.00)$ \\
\hline \multicolumn{4}{|l|}{ Merulinidae } \\
\hline Hydnophora & $0.42(0.83)$ & $0.42(0.83)$ & $0.00(0.00)$ \\
\hline \multicolumn{4}{|c|}{ Dendrophylliidae } \\
\hline Tubastrea & $0.00(0.00)$ & $0.00(0.00)$ & $1.25(1.60)$ \\
\hline \multicolumn{4}{|l|}{ Caryophyllidae } \\
\hline Gyrosmilia & $0.42(0.83)$ & $0.83(0.96)$ & $0.00(0.00)$ \\
\hline Others & 4.17 (1.66) & $4.58(3.70)$ & $1.25(0.83)$ \\
\hline Total & $137.08(34.14)$ & $172.92(22.87)$ & 42.08 (19.50) \\
\hline${ }^{\mathrm{a}}$ Identifiable onl & ly to family 1 & & \\
\hline
\end{tabular}

tively estimating survival until a particular size rather than a particular age. It has previously been shown that the use of size instead of age classes is acceptable for analysing coral population dynamics (Hughes 1984).

\section{RESULTS}

\section{Abundance, recruitment and mortality}

We observed 26 genera of juvenile stony corals at our study sites (Table 1), out of 38 confirmed genera of zooxanthellate stony corals known for the Eilat area (Chadwick-Furman \& Al-Moghrabi 2004); 2 more genera, Plerogyra and Siderastrea, were found on the transects as adults only. Juvenile coral abundance varied almost 4-fold between sites, with a maximum of 173 juvenile corals $\mathrm{m}^{-2}$ at the IUI South site (Tables $1 \& 2$ ). Corals belonging to the family Faviidae were common at all sites, but the relative abundance of genera within this family varied substantially between sites. Unidentified faviids and members of the genera Favia and Favites were common at the 2 northern sites, while those of Cyphastrea and Leptastrea were common at all sites (Table 1). In the family Pocilloporidae, the branching corals Stylophora spp. were abundant at both of the northern sites, but not at Taba. In addition, corals belonging to the genera Porites, Acanthastrea and Platygyra were fairly common at 1 or more sites, while juveniles of the remaining coral types were uncommon to rare (Table 1). Notably, juvenile colonies of Acropora spp. were rare, even though adult corals of this genus were common at both IUI sites (Glassom pers. obs.).

The size structure of the coral community was similar between the 2 northern sites, with small juveniles being most common, and abundance decreasing exponentially with increasing coral size class (Fig. 2). In contrast, at the Taba site there were relatively few small juveniles, and relatively more adult corals $>40 \mathrm{~mm}$ diameter (Fig. 2). At all sites, the smallest size class of 0 to $4 \mathrm{~mm}$ diameter was under-represented (Fig. 2), due either to the difficulty of detecting very small corals on the reef or to mortality of juvenile corals before skeletal deposition rendered them visible.

Coral assemblages within the transects remained similar between sample dates, in that each transect grouped most closely with 'itself' during successive dates, in terms of generic composition (Fig. 3A). Transects within sites also were similar to each other, except for Transect 3 at Taba. However, this transect still was more similar to the other Taba transects than to transects at the other sites (Fig. 3A). Juvenile coral assemblages within most transects were more similar between the April and August 2001 sample dates than 
either date was to the December 2000 sample. This trend was enhanced at the IUI North site, where many corals were concealed by turf algae during December, but were visible in April and August (Fig. 2). In terms of spatial variation, pairwise ANOSIM analysis revealed that the coral assemblage at Taba differed significantly from that at both the North $(r=0.563, p=0.029)$ and South ( $r=0.406, p=0.029)$ IUI sites, but there was no significant difference between the latter 2 sites $(\mathrm{r}=0.104, \mathrm{p}=$ 0.20, Fig. 3).

The total number of juvenile corals per transect remained constant throughout the study (Table 2), except at the IUI North site, where many corals were hidden under a dense layer of turf algae during the initial survey in December.

The large increase that was observed in the total number of corals (Table 2) and of juvenile 'recruits' (Table 3) at this site during the following survey, may have been partly due to the observation of small juvenile colonies that had been present but not visible during the December survey. The ratio of juvenile to adult corals varied from about 20:1 at the IUI North site to 5:1 at Taba (Table 2, Fig. 2).

Despite consistent total numbers of corals over time at most of the sites, there was a substantial turnover of individual coral colonies during the study. New corals recruited to all sites, with the lowest rate at Taba (Table 3A). Unidentified faviid corals comprised most of the recruitment of juveniles during April to August, along with the branching pocilliporid corals Pocillopora spp. and Stylophora spp. (Table 3B). During December to April, faviid corals of various genera also dominated recruitment of juveniles, along with individuals belonging to the genus Stylophora (Table 3B).

Members of most of the coral genera that were common as juveniles (Table 1) also had high rates of recruitment during the study (Table 3B). At both IUI sites, there was a significant correlation between juvenile recruitment and abundance (Fig. 4A,B). In contrast, at the Taba site, juvenile recruitment and abundance were both low (Fig. 4C).

Pairwise ANOSIM (Clarke \& Warwick 2001) revealed that assemblages of new juvenile recruits at Taba differed from those at both the South $(\mathrm{r}=0.315, \mathrm{p}$ $=0.017)$ and North $(r=0.396, p=0.008)$ IUI sites. In contrast, the generic composition did not differ between the 2 IUI sites $(r=0.115, p=0.21)$. Coral generic patterns of juvenile recruitment were seasonal: they differed significantly between the December to April period and the April to August period ( $\mathrm{r}=$ 0.307, $\mathrm{p}=0.002$, Table 3B).
The abundance of juvenile corals belonging to each genus did not vary significantly with their survival rates at any of the 3 sites examined (Fig. 4D to F). Juvenile survival was high for most coral genera at all sites, except for corals belonging to the genus Stylophora (Fig. 4D-F). Between 9 and $11 \%$ of coral colonies died every 4 mo $(9.36 \pm 4.22,10.02 \pm 3.47$ and $11.01 \pm 5.44 \%$ for IUI North, IUI South and Taba, respectively) with most mortality occurring in small colonies $<10 \mathrm{~mm}$ diameter (Fig. 5). High mortality rates of $33 \%$ every 4 mo were observed in very small corals $(<6 \mathrm{~mm}$ diameter) in some of the transects. Annual mortality rates for all juvenile corals were estimated at 27 to $33 \% \mathrm{yr}^{-1}$.
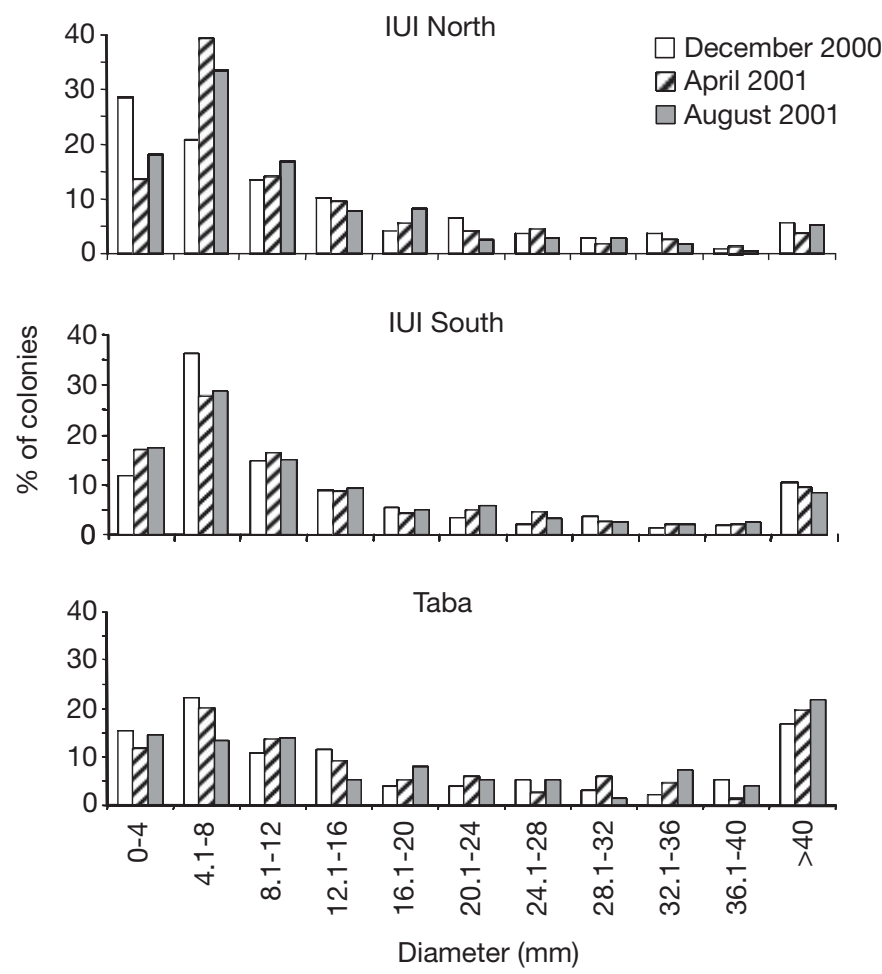

Fig. 2. Size-frequency distributions of coral colonies at 3 sites and 3 sample intervals on reefs at Eilat 


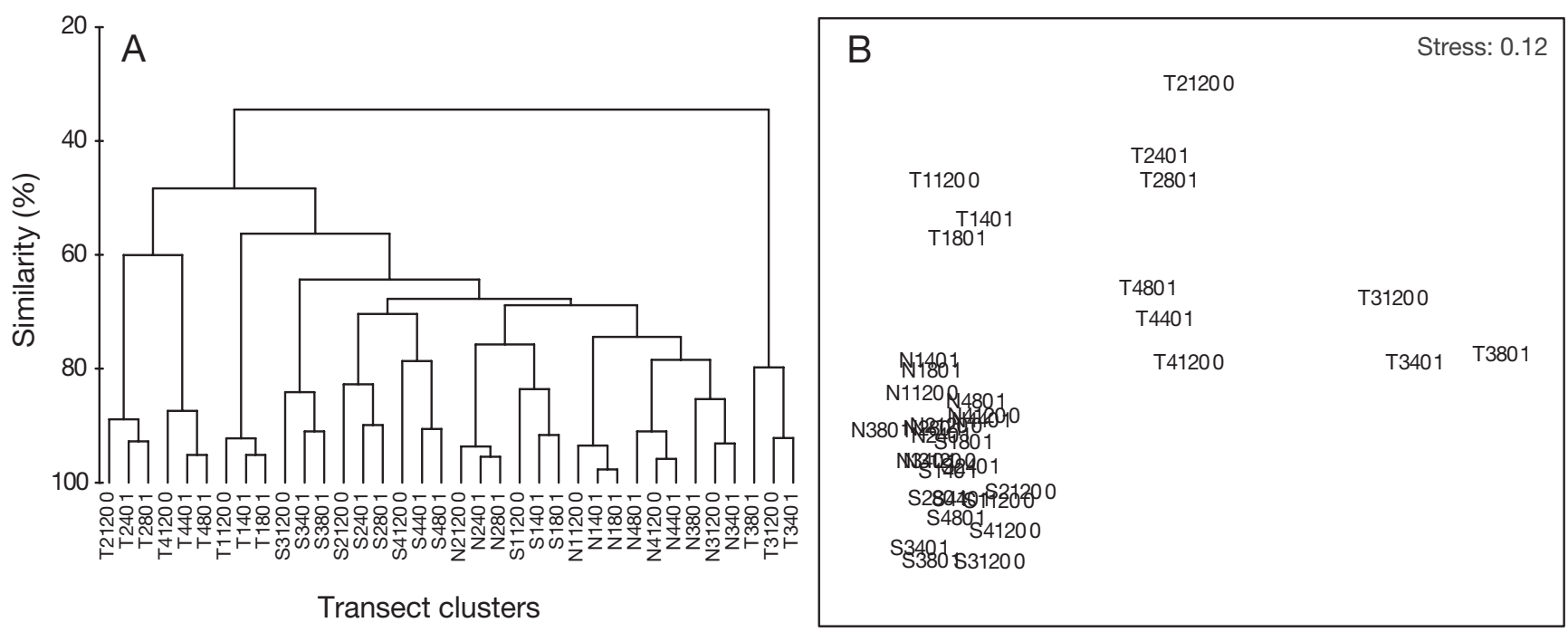

Fig. 3. (A) Dendrogram and (B) MDS plot showing overall patterns of juvenile coral abundance on reefs at Eilat. In (A), abscissa = site name (N: IUI North, S: IUI South, T: Taba; followed by transect number $(1,2,3$, or 4), month and year (2000 or 2001). For example, T2401 = Taba, Transect 2, April 2001

Table 3. (A) Recruitment and mortality rates (mean $\mathrm{m}^{-2}$ ) of juvenile stony corals at 3 sites near Eilat, during 2 consecutive 4 mo intervals; (B) total numbers of newly observed juvenile recruits of 16 genera, at each site and for each sampling interval

\begin{tabular}{|c|c|c|c|c|c|c|}
\hline \multicolumn{3}{|c|}{ (A) Recruitment and mortality } & & \\
\hline $\begin{array}{l}\text { Time interval } \\
\text { (mo-yr) }\end{array}$ & $\begin{array}{l}\text { - IUI No } \\
\text { ecruited }\end{array}$ & Died & $\begin{array}{l}\text {-IUI Sol } \\
\text { Recruited }\end{array}$ & Died & $\begin{array}{l}- \text { Taba } \\
\text { Recruited }\end{array}$ & $\overline{\text { Died }}$ \\
\hline $\begin{array}{l}\text { Dec-00 to } \\
\text { Apr-01 }\end{array}$ & 60.84 & 9.17 & 27.08 & 24.17 & 9.58 & 6.66 \\
\hline $\begin{array}{l}\text { Apr-01 to } \\
\text { Aug-01 }\end{array}$ & 22.08 & 20.42 & 20.83 & 19.17 & 4.58 & 7.08 \\
\hline Total & 82.92 & 29.59 & 47.91 & 43.34 & 14.16 & 13.74 \\
\hline \multicolumn{7}{|l|}{ (B) Total new recruits } \\
\hline & \multicolumn{2}{|c|}{ IUI North } & \multicolumn{2}{|c|}{ IUI South } & \multicolumn{2}{|c|}{ Taba } \\
\hline & $\begin{array}{c}\text { Dec- } \\
\text { Apr }\end{array}$ & $\begin{array}{c}\text { May- } \\
\text { Aug }\end{array}$ & $\begin{array}{c}\text { Dec- } \\
\text { Apr }\end{array}$ & $\begin{array}{c}\text { May- } \\
\text { Aug }\end{array}$ & $\begin{array}{c}\text { Dec- } \\
\text { Apr }\end{array}$ & $\begin{array}{c}\text { May- } \\
\text { Aug }\end{array}$ \\
\hline Acanthastrea & 4 & 4 & 1 & 0 & 1 & 1 \\
\hline Coscinarea & 3 & 1 & 1 & 0 & 0 & 0 \\
\hline Cyphastrea & 10 & 1 & 5 & 3 & 3 & 1 \\
\hline Favia & 30 & 1 & 3 & 1 & 0 & 0 \\
\hline Goniastrea & 6 & 1 & 1 & 0 & 0 & 0 \\
\hline Favites & 14 & 5 & 6 & 0 & 4 & 0 \\
\hline Leptastrea & 10 & 4 & 22 & 5 & 2 & 0 \\
\hline Platygyra & 3 & 2 & 0 & 1 & 0 & 0 \\
\hline Unidentified faviids & s 26 & 11 & 9 & 15 & 0 & 5 \\
\hline Montipora & 1 & 0 & 1 & 0 & 3 & 1 \\
\hline Pavona & 0 & 0 & 1 & 0 & 4 & 0 \\
\hline Pocillopora & 0 & 8 & 1 & 4 & 1 & 1 \\
\hline Stylophora & 26 & 6 & 11 & 15 & 4 & 1 \\
\hline Porites & 4 & 3 & 1 & 2 & 0 & 0 \\
\hline Psammocora & 0 & 0 & 2 & 1 & 0 & 0 \\
\hline Other corals & 5 & 1 & 0 & 1 & 1 & 0 \\
\hline
\end{tabular}

Colonies that settled in April suffered significantly higher mortality between April and August than did older juvenile corals that were already present in December $\left(\chi^{2}\right.$ test, $\mathrm{df}=1, \chi^{2}=20.344, \mathrm{p}$ $<0.0001)$. Mortality rates of juvenile corals decreased with increasing size (Pearson's correlation, $\mathrm{r}=-0.42, \mathrm{p}=$ 0.0002, Fig. 5). Only 9 of the 196 corals that died during the survey were adults, with a diameter $>40 \mathrm{~mm}$ (Fig. 5). Of these, 4 were colonies of Stylophora pistillata, the largest of which measured $162 \mathrm{~mm}$ in diameter. The generic composition of dead corals varied between the Taba and IUI South sites (ANOSIM, $r=0.276, p=0.046$ ) but not between the 2 IUI sites $(r=0.135$, $\mathrm{p}=0.144$ ) or between the IUI North and Taba sites $(r=0.12, p=0.169)$. Generic patterns of juvenile coral mortality were similar in April and August ( $\mathrm{r}=$ 0.028, $\mathrm{p}=0.384$ ).

Survival curves did not vary between sites for most of the common coral genera, but did vary for colonies of Acanthastrea spp. and Stylophora spp. (Table 4). For all genera combined, survival curves did not vary significantly between sites (Table 4, Fig. 6). In particular, Stylophora spp. had relatively low survival rates, and Favites spp. survival was relatively high (Fig. 6). 


\section{Growth rates}

A repeated-measures ANOVA, using time intervals as the repeated measure, revealed no significant variation in the growth rates of stony corals among genera or families, or between reef sites (Table 5). Thus, corals from all sites and families were pooled for the purpose of comparing growth rates during December to April with those during April to August. Initial coral diameter was not significantly correlated with growth rate (Pearson's correlation, $\mathrm{r}=0.114, \mathrm{p}=0.162$ ), and was therefore excluded from the repeated-measure analysis. The corals grew at rates of $0.38( \pm 0.02) \mathrm{mm} \mathrm{mo}^{-1}$ mean diameter between December and April and $0.44( \pm 0.04) \mathrm{mm} \mathrm{mo}^{-1}$ between April and August, with growth being significantly slower during the former period (1-way ANOVA, $\mathrm{N}=571, \mathrm{df}=1, F=7.47$, $\mathrm{p}=0.006)$. Thus, growth rate $\mathrm{yr}^{-1}$ was about $4.9 \mathrm{~mm}$ in diameter for all corals combined.

Few juvenile corals reached the size threshold (40 mm diam.) comprising entry to the adult population during the $8 \mathrm{mo}$ of this study $(9$ colonies at Taba, 8 at IUI South and only 3 at IUI North made the transition, Fig. 2). Of the 9 colonies at Taba, 6 reached $40 \mathrm{~mm}$ diameter between December 2000 and April 2001, indicating an increase in the largest size class at this site between the 2 sample dates (Fig. 2).

\section{DISCUSSION}

The juvenile coral abundances observed in the northern Red Sea during this study are the highest recorded to date for coralreef habitats worldwide. We observed abundances ranging from a minimum of 42 juvenile corals $\mathrm{m}^{-2}$ at Taba in August 2001 to a maximum of $171 \mathrm{~m}^{2}$ at the IUI South site in April 2001 (Table 2). All other studies on juvenile coral abundances have been conducted in the Caribbean Sea, and have recorded only 15 to 18 juveniles $\mathrm{m}^{-2}$ at Curaçao and Bonaire (Bak \& Engel 1979), 6 to 44 at Barbados (Wittenberg \& Hunte 1992) and 3.7 (Chiappone \& Sullivan 1996) to a maximum of 40 (Edmunds et al. 2004) in Florida. Densities of up to 212 juvenile coral colonies $\mathrm{m}^{-2}$ were observed in some quadrats by Edmunds (2000) in the US Virgin Islands, but median densities per site always were $<35$ colonies $\mathrm{m}^{-2}$. To our knowledge, the present study is the first to assess the abundance of juvenile corals belonging to all genera present in an Indo-Pacific reef-coral assemblage. Other reefs in this region are also expected to have higher juvenile coral abundances than do Caribbean reefs, which in general experience low recruitment relative to those examined in the Indo-Pacific region (reviewed by Glassom et al. 2004). Our selection of areas with low adult-coral cover (see 'Materials and methods') may also have resulted in higher juvenile coral abundances than would be expected for randomly selected areas on Indo-Pacific coral reefs.

The juvenile abundance patterns of stony-coral genera varied with their recruitment on the 2 IUI reefs

IUI North

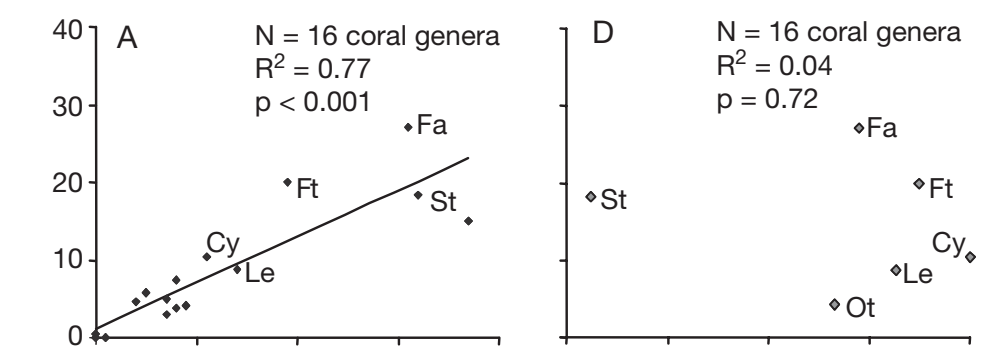

IUI South
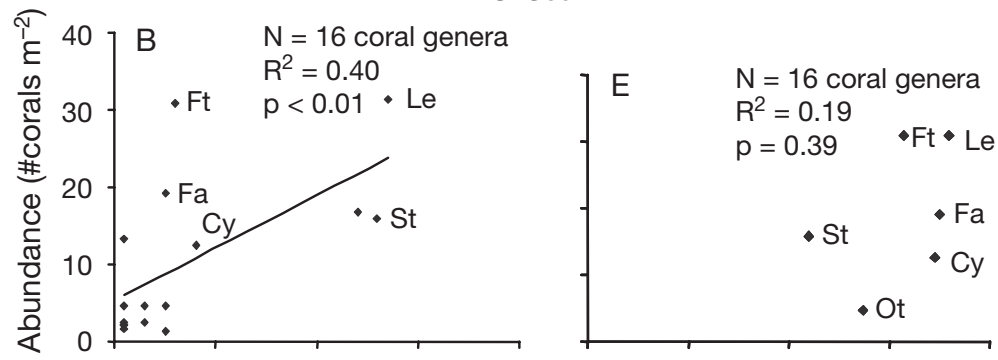

Taba

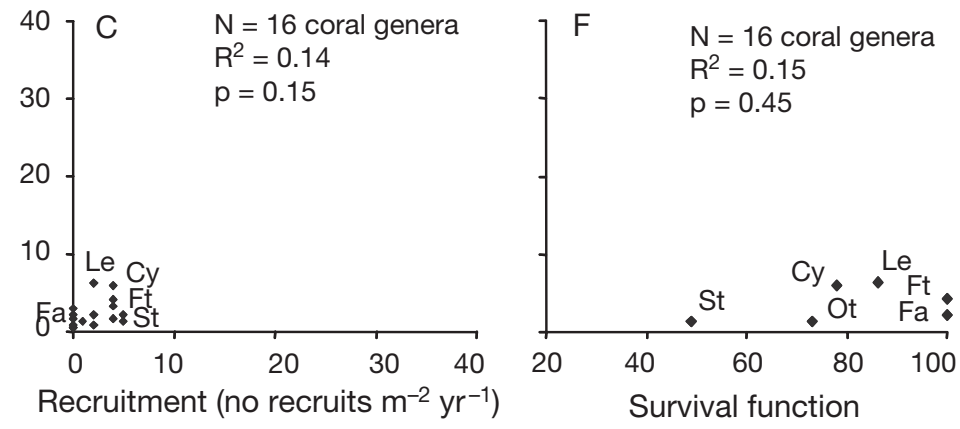

Fig. 4. Variation in the abundance of major genera of stony corals, and $(\mathrm{A}-\mathrm{C})$ rates of juvenile recruitment and $(\mathrm{D}-\mathrm{F})$ survival at 3 coral-reef sites near Eilat. Fa: Favia, Ft: Favites, Le: Leptastrea, Cy: Cyphastrea, St: Stylophora. In (A-C) 11 unlabelled data points represent other stony-coral genera, in (D-F), these are grouped as 'others' (Ot). Survival distribution functions are presented for juvenile corals at the mid-point of their size range (about $18 \mathrm{~mm}$ colony diameter, see Fig. 6). Abundance varies significantly with recruitment but not with survival at both IUI sites; coral abundance and recruitment were both low at Taba, but survival was not 


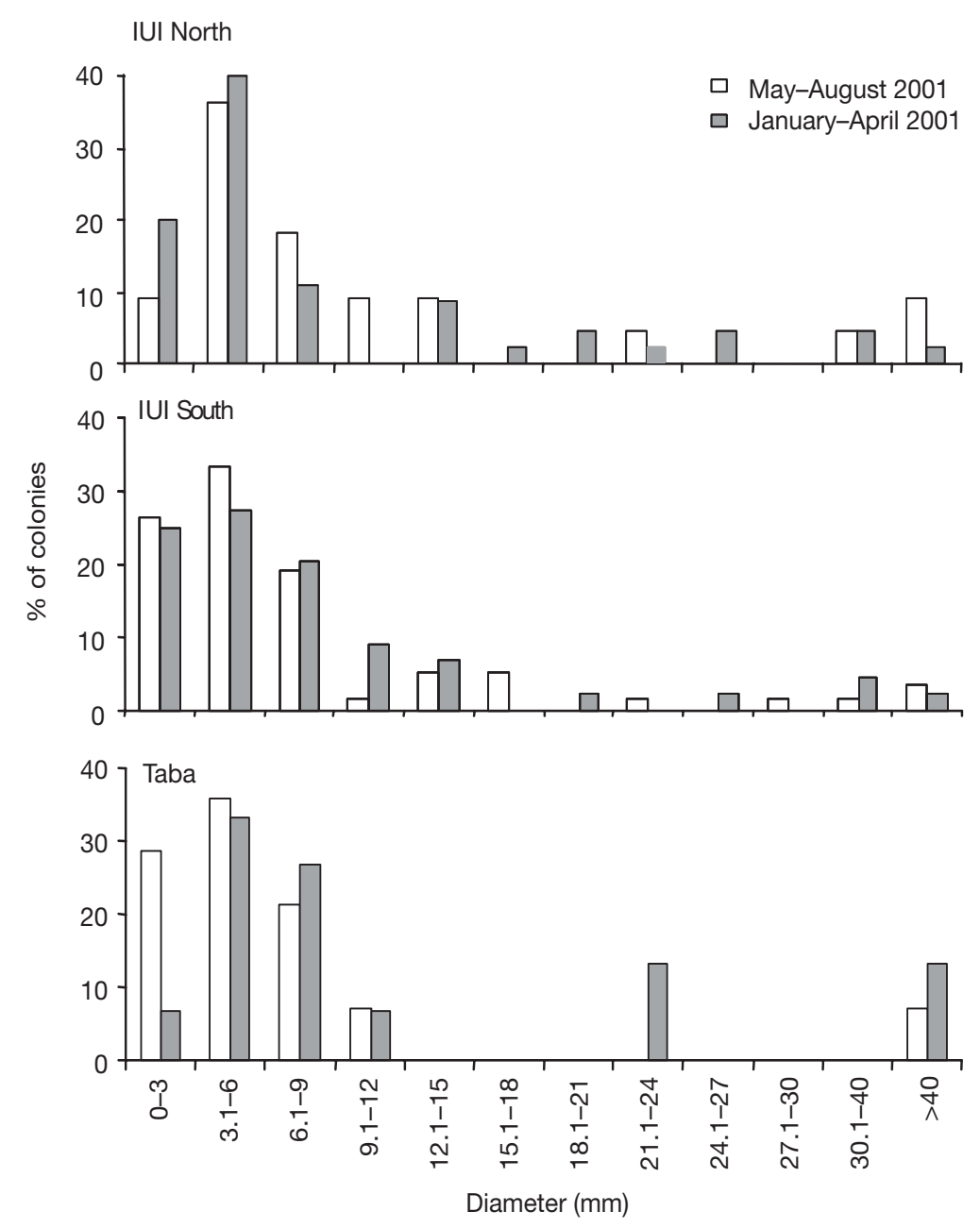

Fig. 5. Variation in number of dead corals as a function of coral size class for each site and sampling interval

Table 4. Tests of homogeneity of survival rates for juvenile stony corals among 3 reef sites at Eilat, over 8 mo (December 2000 to August 2001), and among most common coral genera. Both log-rank and Wilcoxon tests were applied: former is weighted toward early survival, latter toward late survival

\begin{tabular}{|c|c|c|c|c|}
\hline & \multicolumn{2}{|c|}{ Log-rank test } & \multicolumn{2}{|c|}{ Wilcoxon test } \\
\hline & $\chi^{2}$ & $\mathrm{p}$ & $\chi^{2}$ & $\mathrm{p}$ \\
\hline \multicolumn{5}{|c|}{ Between sites df $=2$} \\
\hline Acanthastrea & 11.33 & 0.0035 & 11.33 & 0.0035 \\
\hline Cyphastrea & 6.13 & 0.047 & 6.27 & 0.044 \\
\hline Favia & 2.24 & 0.327 & 1.99 & 0.370 \\
\hline Favites & 0.62 & 0.733 & 0.67 & 0.714 \\
\hline Leptastrea & 1.52 & 0.467 & 2.07 & 0.356 \\
\hline Stylophora & 15.70 & 0.0004 & 14.43 & 0.0007 \\
\hline Others & 0.48 & 0.786 & 0.87 & 0.648 \\
\hline Total & 1.37 & 0.505 & 2.78 & 0.249 \\
\hline \multicolumn{5}{|c|}{ Between genera df $=6$} \\
\hline & 117.65 & $<0.0001$ & 90.85 & $<0.0001$ \\
\hline
\end{tabular}

(Table 1, Fig. 4). The relative abundance of juvenile corals among sites also reflects their rates of settlement on artificial substrata at these sites (Glassom et al. 2004). Juvenile growth and mortality rates were similar among genera, with few exceptions. Thus, the generic-level community structure of corals at least up to several years old on these reefs appears to be determined largely by variation in recruitment of juveniles, rather than by juvenile mortality.

The 2 sites (IUI) in our study that were separated by $<200 \mathrm{~m}$ experienced highly similar patterns of juvenile recruitment and community structure. In contrast, Taba differed from the other sites in both number and genera of juveniles, and also in the overall coral communities that developed, even though Taba was separated from the other 2 sites by only $2 \mathrm{~km}$. Coral assemblages on all 3 reefs were highly dynamic, with an estimated turnover rate of about $30 \%$ of juveniles $\mathrm{yr}^{-1}$ (see 'Results').

Coral recruitment may vary widely at small spatial and temporal scales (Glassom et al. 2004), the relatively low recruitment we observed at Taba is not surprising (Table 3). All size classes of juvenile corals, some approaching $40 \mathrm{~mm}$ in diameter and thus being several years old, were also less abundant at Taba than at the other 2 sites examined (Table 2, Fig. 2), indicating that low recruitment of juvenile corals may be a persistent feature at this site (Fig. 4C), but that low survival is not (Figs. 4F \& 6). Since coral survival curves did not differ significantly between Taba and the other sites for all corals combined (Fig. 6), the low juvenile coral abundance must be attributed to persistently low recruitment. Causes of low juvenile recruitment at Taba are not clear, since this site is distant from putative point-sources of pollu-

Table 5. Model 1, repeated-measures ANOVA of growth rates of juvenile corals among genera, families and reef sites at Eilat, using sampling periods as repeated measure. Parentheses denote nesting of genera within each coral family

\begin{tabular}{|lccc|}
\hline Variable & df & $F$ & $\mathrm{p}$ \\
\hline Site & 2 & 1.18 & 0.308 \\
Genus (Family) & 24 & 1.06 & 0.390 \\
Family & 4 & 0.40 & 0.811 \\
Site $\times$ Genus (Family) & 8 & 0.64 & 0.745 \\
Site $\times$ Family & 16 & 0.64 & 0.845 \\
& & & \\
\hline
\end{tabular}


tion in the area, including the port and city of Eilat (Fig. 1), and is not among the areas most heavily utilized by divers (Zakai \& Chadwick-Furman 2002). Variation in substratum type and orientation potentially play a role in recruitment differences on reefs (see Sato 1985), suggesting that the vertical orientation of the transects at Taba may have influenced recruitment rates of juveniles. The coral rock that is the primary settlement surface at Taba was almost free of coralline or other algae which in some cases, act as a settlement cue for coral larvae (Harrison \& Wallace 1990). However, settlement rates on ceramic tiles were also lower at Taba than at either of the 2 northern sites (Glassom et al. 2004), implying that factors other than substratum are involved. Moreover, there is little horizontal substratum available at Taba, so the sites chosen during this study accurately reflect the substratum available for recruitment. If the juvenile recruitment rates observed during this study are typical for Taba, it is likely that coral population growth, especially during reef recovery following a disturbance, would be considerably lower here than at the other 2 sites examined.

The mortality rates observed here for juvenile corals are within the range recorded by Shlesinger \& Loya (1991) at Eilat, and Miller et al. (2000) in Florida, and are slightly lower than those recorded for juvenile corals in Curaçao and Bonaire (Bak \& Engel 1979). Mortality of 66 to $86 \%$ has been reported for coral spat settled on artificial substrata and transferred to the reef (Babcock 1985), but these values are not comparable with those in our study, since our method did not allow observation of spat immediately following settlement. Our juvenile mortality rates were similar for both survey intervals, and thus were extrapolated to obtain annual mortality estimates (see 'Results').

The rates of juvenile coral recruitment for the $8 \mathrm{mo}$ period probably encompassed total recruitment for the entire year, since at Eilat recruitment is unlikely during the fall period (Glassom et al. 2004). Of the coral genera for which reproductive cycles have been studied at Eilat, only the rare genera Seriotopora and Alveopora are known to release gametes between August and December (Shlesinger et al. 1998). The temporal patterns of juvenile recruitment observed here did not in all cases match the known seasons for larval production by coral genera at Eilat. However, the rate of skeletal deposition by coral spat after settlement varies
-- North IUI

Stylophora

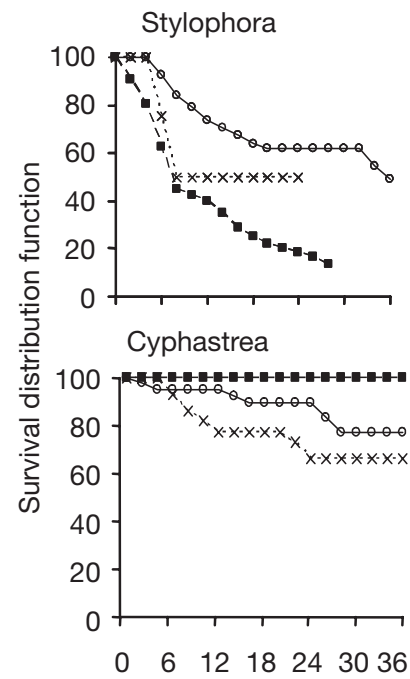

Favia
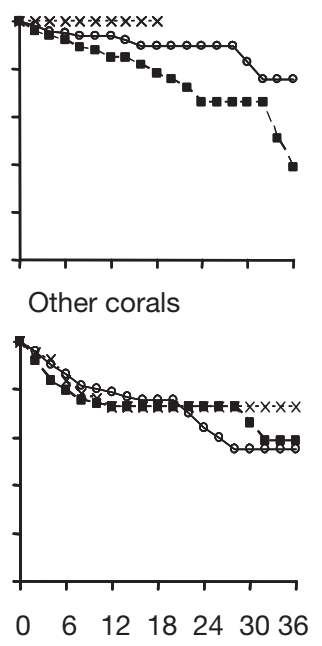

Coral colony diameter $(\mathrm{mm})$ $\rightarrow$ South IUI $\cdots \times$.. South IUI

Favites

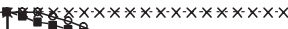

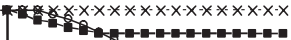
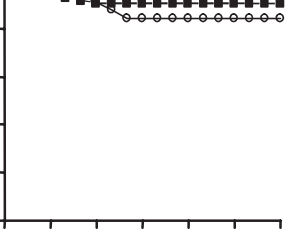

Total

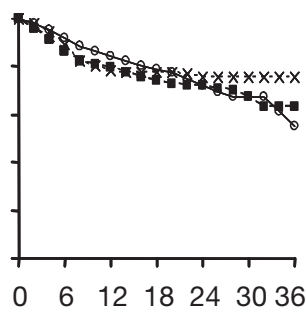

Fig. 6. Survival curves of selected common genera of juvenile stony corals at Fate of juvenile corals was followed on the reef, and survival in each size class was recorded at the end of 8 mo. Survival Distribution Function was 1999)

widely between families. Deposition by colonies of faviid corals is particularly slow (Babcock et al. 2003), and thus most faviid polyps became visible on the substratum only in December to April (Table 3B), about 6 mo after their known reproductive season of July to August (Shlesinger et al. 1998). Low juvenile recruitment rates (Fig. 4B) in some of the common coral genera (Table 1) may indicate highly sporadic recruitment, or population growth mainly via vegetative propagation.

In general, rates of coral mortality decreased with increasing colony size, similar to patterns observed at other reef localities (Babcock 1985, Bak \& Meesters 1998, Miller et al. 2000). Our survival curves (Fig. 6) were based on juvenile colonies that had been followed since the start of the study. The relatively large size of many of these colonies may have led to underestimates of projected mortality, especially for genera where few, new small colonies settled during the study period, for example the genera Acanthastrea and Stylophora at Taba. Survival curves differed significantly between sites for these genera (Table 4), but interpretation is hindered by their relative scarcity at Taba (Fig. 4). The relatively low survival of Stylophora spp. juveniles at all sites (Fig. 4D-F) may explain in part why their high recruitment (Glassom et al. 2004, and present Fig. 4A,B) has not resulted in a higher abundance of this genus (Table 1). Members of the genus Stylophora are known to be weedy corals, with high 
rates of recruitment, growth and mortality (Loya 1976a,b, Glassom et al. 2004), Figs. 4 \& 6), and are thus expected to show rapid population turnover on coral reefs. The only other genus for which survival curves differed significantly between sites, Cyphastrea, had relatively low survival at Taba, where it was nonetheless one of the most abundant genera (Table 1). Thus, juvenile mortality does not appear to account for the abundance patterns of this genus. In contrast, colonies of the genera Favia and Favites were among the most abundant corals at the 2 northern sites (Table 1), and also had high rates of survival at all sites (Figs. 4 \& 6). We conclude that patterns of juvenile recruitment may be more important than mortality in determining differences in coral community structure among the sites examined. The density-independent mortality patterns of juvenile corals, inferred here by the similar rates of mortality at sites with substantially different numbers of juvenile corals, are thought to indicate recruitment limitation of adult coral populations (Connell 1985, Hughes 1990).

The monthly growth rates of juvenile corals in our study are equivalent to a mean increase in diameter of approximately $4.9 \mathrm{~mm} \mathrm{yr}^{-1}$. This is slightly faster than combined growth rates reported for some planulating and gamete-spawning corals (Harrison \& Wallace 1990, Edmunds 2000), but similar to that of some massive corals in Australia (Babcock 1985), and slower than juvenile growth in Montastrea annularis (Hudson et al. 1994), Agaricia agaricites (Bak \& Engel 1979) and several species of branching corals (Babcock 1985, Sato 1985). Overall, growth rates of juvenile corals at Eilat occur within the range of values recorded at other reef locations.

Since growth rates did not vary significantly among genera of juvenile corals in our study (Table 5), they cannot be used to explain patterns of coral abundance. Juvenile-coral growth rates have been found to vary between species and genera in other studies (Babcock 1985, Harrison \& Wallace 1990). They may not have been detected here (in part) because, growth rates can also vary widely within coral species, and depend on a range of environmental factors including sedimentation (Bak \& Engel 1979), microhabitat differences (Sato 1985, Edmunds et al. 2004) and anthropogenic disturbances (Hudson et al. 1994). Only corals with no partial tissue mortality were used to determine growth rates in the present study; however, corals may repair small lesions within short periods (Bak \& Meesters 1998), and some may have become damaged and recovered between measurements, thus affecting growth rates. In addition, we observed some coral colonies to shrink between measurements, as has been reported for juvenile corals in the Caribbean Sea (Edmunds 2000, Edmunds et al. 2004). Shrinkage may be an effect of colony fission or partial mortality, followed by overgrowth or erosion of the skeleton, which renders these processes undetectable. Thus, our lack of discernible variation in growth between genera may have resulted from various ecological processes operating on juvenile corals. In contrast to reports in some other studies (Edmunds et al. 2004), the initial diameter of juvenile corals did not significantly affect the growth rate.

Coral recruitment will not necessarily be highest where conditions are favorable for rapid coral growth, since such these conditions also may favor the growth of algae and other fast-growing competitors of coral spat (Birkeland 1977). Juvenile colonies are known to experience reduced survival and growth rates in the presence of filamentous algae (Sato 1985). However, the dense mat of turf algae that covered the substrate at the IUI North site during December 2000 (see 'Results') did not appear to influence coral growth rates. Since the 2 IUI sites were $<200 \mathrm{~m}$ apart, it is not clear why only 1 was affected by the algal bloom. The observed similarities in coral generic composition and growth rates between these 2 sites (see 'Results' and Table 1) indicate that the algal bloom may have been too transient to have had a strong effect on these parameters.

We conclude that variation in juvenile coral abundance among genera appears to be driven primarily by variation in larval recruitment, since this did not vary with rates of juvenile growth or mortality (Fig. 4, Table 5). We did not detect actual larval settlement because, despite the use of a magnifying glass to examine the substrate, it is likely that even the smallest corals observed were already several months old (Fig. 2). Up to $99 \%$ mortality of newly settled spat may occur before the primary polyp stage is reached at 1 to 6 mo, depending on the coral genus and family (Shlesinger \& Loya 1991). Thus, mortality of coral spat soon after settlement would not have been detected during the present study, and may have influenced overall community structure. Overall, juvenile growth and mortality beyond the first few months following settlement were not major indicators of differences in juvenile community structure between our sites, at the spatial and temporal scales examined (Fig. 4, Table 5). In a study in the Caribbean Sea, Edmunds et al. (2004) similarly found that microhabitat choice did not affect the survival or growth of juvenile corals.

In assessment of community stability, persistence is not defined by the longevity of individuals (Connell \& Sousa 1983 and references therein), but rather by replacement rates of adults by juveniles. Ideally, patterns of replacement should be observed or predicted over 1 turnover of all individuals, and at a spatial scale equivalent to the minimum area at which a population is stable (Connell \& Sousa 1983). This approach clearly 
is impractical in the case of scleractinian corals - at least on the temporal scale, due to colony longevity. An alternative is to compare the composition of the juvenile assemblage with that of the adult assemblage, particularly if stability is defined in terms of the persistence of such relationships rather than constancy of numbers (Connell \& Sousa 1983). Correlations between juvenile and adult coral communities have been observed on some Caribbean reefs (Chiappone \& Sullivan 1996), but not on others (Smith 1992, Edmunds 2000), and no published evidence exists on such patterns in the Indo-Pacific region. While quantitative data on adult coral communities to genus level were not collected during the present study, some patterns did emerge. First, the low number of juvenile Acropora spp. at the IUI sites was in contrast to the high abundance of adult colonies at these sites (D. Glassom pers. obs.). Stylophora, one of the most abundant genera in adult coral populations at the IUI sites (Rinkevich \& Loya 1987), was also abundant in the juvenile population, but less so than were several genera of faviid corals (Table 1). Stylophora spp. juveniles had one of the lowest survival rates of all genera for which curves were calculated (Fig. 6), and adult colonies are short-lived relative to most coral taxa (Rinkevich \& Loya 1984). The reef at these sites is young and still developing (Loya 1976a), and changes in species composition from weedy r-strategy corals such as Stylophora (Loya 1976b), to more long-lived massive corals, is likely to occur. If the relative composition of the adult versus juvenile coral assemblages at a site is a realistic predictor of future community structure it appears that, in view of the present abundance of juvenile faviid corals, this family will become numerically dominant at the 2 IUI sites over time. Faviid corals are generally resistant to stress and instability, and are often over-represented at marginal reef sites relative to acroporids (Hughes \& Connell 1999, Bellwood \& Hughes 2001). The abundance of faviid juveniles on our transects may therefore indicate stressful conditions on these reefs.

Our results and those of our previous study (Glassom et al. 2004) show that juvenile coral recruitment varies widely among sites at Eilat, and does not follow a strict north to south gradient. Low recruitment and reef recovery at the Coral Beach Nature Reserve (CBNR) of Eilat may be due in part to lack of a seed population of adult corals north of that area, in contrast to the IUI site, which may be seeded by the CBNR reefs (Fig. 1). Thus, coral recruitment and community recovery patterns are related in part to their proximity to upstream seed-areas (Glassom et al. 2004). We have demonstrated herein, that patterns of juvenile coral recruitment vary widely among sites at Eilat and do not appear to correlate with a north to south gradient, since Taba had lower recruitment than did the 2 northern sites. Simulation models have demonstrated that increased recruitment can significantly augment coral population sizes even if rates of growth and survival do not change (Hughes 1990). Modeling of coral population growth at Eilat using parameters measured in the present study may contribute to testing the hypothesis that variable recruitment among sites is a major determinant of coral community recovery following disturbance on these reefs.

Acknowledgements. We thank the staff of the Interuniversity Institute for Marine Science in Eilat for logistical support during this study. Funding was provided by a grant from USAID MERC via the Red Sea Marine Peace Park Program, and by grants from Bar Ilan University to N.E.C. This research was submitted in partial fulfillment of the requirements for a doctoral degree at Bar Ilan University by D.G. Comments by 3 anonymous reviewers greatly improved the manuscript.

\section{LITERATURE CITED}

Babcock RC (1985) Growth and mortality in juvenile corals (Goniastrea, Platygyra and Acropora): the first year. Proc 5th Int Coral Reef Congr 4:355-360

Babcock RC, Baird AH, Piromvaragorn S, Thomson DP, Willis BL (2003) Identification of scleractinian coral recruits from Indo-Pacific reefs. Zool Stud 42:211-226

Bak RPM, Engel MS (1979) Distribution, abundance and survival of juvenile hermatypic corals (Scleractinia) and the importance of life-history strategies in the parent coral community. Mar Biol 54:341-352

Bak RPM, Meesters EH (1998) Coral population structure: the hidden information of colony size-frequency distributions. Mar Ecol Prog Ser 162:301-306

Bellwood DR, Hughes TP (2001) Regional-scale assembly rules and biodiversity of coral reefs. Science 292: 1532-1534

Birkeland C (1977) The importance of biomass accumulation in early successional stages of benthic communities to the survival of coral recruits. Proc 3rd Int Coral Reef Symp 1:15-21

Branch GM (1984) Competition between marine organisms: ecological and evolutionary implications. Oceanogr Mar Biol Annu Rev 22:429-593

Caley MJ, Car MH, Hixon MA, Hughes TP, Jones GP, Menge BA (1996) Recruitment and the local dynamics of open marine populations. Annu Rev Ecol Syst 27:477-500

Chadwick-Furman NE, Goffredo S, Loya Y (2000) Growth and population dynamic model of the reef corals Fungia granulosa Klunzinger, 1879 at Eilat, northern Red Sea. J Exp Mar Biol Ecol 249:199-218

Chadwick-Furman NE, Al-Moghrabi S (2004) Annotated list of scleractinian corals of the northern Gulf of Aqaba, Red Sea. Report of the Red Sea Marine Peace Park Program. Interuniversity Institute for Marine Science, Eilat

Chiappone M, Sullivan KM (1996) Distribution, abundance and species composition of juvenile scleractinian corals in the Florida reef tract. Bull Mar Sci 58:555-569

Clarke KR, Warwick RM (2001) Change in marine communites: an approach to statistical analysis and interpretation, 2nd edn. Bourne Press, Bournemouth

Connell JH (1985) The consequences of variation in initial set- 
tlement vs. post-settlement mortality in rocky intertidal communities. J Exp Mar Biol Ecol 93:11-45

Connell JH, Sousa WP (1983) On the evidence needed to judge ecological stability or persistence. Am Nat 121: 789-824

Connell JH, Hughes TP, Wallace CC (1997) A 30 year study of coral abundance, recruitment and disturbance at several scales in space and time. Ecol Monogr 67:461-488

Eckman JE (1996) Closing the larval loop: linking larval ecology to the population dynamics of marine benthic invertebrates. J Exp Mar Biol Ecol 200:207-237

Edmunds PJ (2000) Patterns in the distribution of juvenile corals and coral reef community structure in St John, US Virgin Islands. Mar Ecol Prog Ser 202:113-124

Edmunds PJ, Aronson RB, Swanson DW, Levitan DR, Precht WF (1998) Photographic versus visual census techniques for the quantification of juvenile corals. Bull Mar Sci 62: 937-946

Edmunds PJ, Bruno JF, Carlon DB (2004) Effects of depth and microhabitat on growth and survivorship of juvenile corals in the Florida Keys. Mar Ecol Prog Ser 278:115-124

Fishelson L (1973) Ecology of coral reefs in the Gulf of Aqaba (Red Sea) influenced by pollution. Oecologia 12:55-67

Glassom D (2002) Reproductive ecology and reef dynamics: a study on corals at Eilat, northern Red Sea. PhD thesis, Bar Ilan University, Israel

Glassom D, Chadwick-Furman NE, Zakai D (2004) Coral recruitment: a spatio-temporal analysis along the coastline at Eilat, northern Red Sea. Mar Biol 144:641-651

Goffredo S, Chadwick-Furman NE (2001) Abundance and distribution of mushroom corals (Scleractinia: Fungiidae) on a coral reef at Eilat, northern Red Sea. Bull Mar Sci 66: 241-254

Grosberg RK, Levitan DR (1992) For adults only? Supply-side ecology and the history of larval biology. Trends Ecol Evol 7:130-133

Harrison PL, Wallace CC (1990) Reproduction, dispersal and recruitment of scleractinain corals. In: Dubinsky Z (ed) Ecosystems of the world Vol 25. Coral reefs. Elsevier, Amsterdam, p 133-207

Holm ER (1990) Effects of density-dependent mortality on the relationship between recruitment and larval settlement. Mar Ecol Prog Ser 60:141-146

Hudson JH, Kirby JH, Halley, RB Kindinger JL (1994) Environmental implications of growth rate changes in Montastrea annularis: Biscayne National Park, Florida. Bull Mar Sci 54:647-699

Hughes TP (1984) Population dynamics based on individual size rather than age: a general model with a reef coral example. Am Nat 123:778-795

Hughes TP (1989) Community structure and diversity of coral reefs: the role of history. Ecology 70:275-279

Hughes TP (1990) Recruitment limitation, mortality and population regulation in open systems: a case study. Ecology 71:12-20

Hughes TP, Connell JH (1999) Multiple stressors on coral reefs: a long term perspective. Limnol Oceanogr 44:932-940

Hughes TP, Baird AH, Dinsdale EA, Moltschaniwskyj NA, Pratchett MS, Tanner JE, Willis BL (2000) Supply-side ecology works both ways: the link between benthic adults, fecundity and larval recruits. Ecology 81(8):2241-2249

Editorial responsibility: Otto Kinne (Editor-in-Chief), Oldendorf/Luhe, Germany
LLoya Y (1976a) Settlement, mortality and recruitment of a Red Sea scleractinian coral population. In: Mackie GO (ed) Coelenterate ecology and behavior. Plenum, New York, p 89-100

Loya Y (1976b) The Red Sea coral Stylophora pistillata is an strategist. Nature 259:478-480

Loya Y (1990) Changes in a Red Sea coral community structure: a long-term case history study. In: Woodwell GM (ed) The earth in transition: patterns and processes of biotic impoverishment. Cambridge University Press, New York, p 369-384

Miller MW, Weil E, Szmant AM (2000) Coral recruitment and juvenile mortality as structuring factors for reef benthic communities in Biscayne National Park, USA. Coral Reefs 19:115-123

Rinkevich B, Loya Y (1984) Senescence and dying signals in a reef building coral. Experientia 42:320-322

Rinkevich B, Loya Y (1987) Variability in the pattern of sexual reproduction of the coral Stylophora pistillata at Eilat, Red Sea: a long term study. Biol Bull (Woods Hole) 173: 335-344

Rogers CS, Fitz CH, Gilnack M, Beets J, Hardin J (1984) Scleractinian coral recruitment patterns at Salt River submarine canyon, St. Croix, US Virgin Islands. Coral Reefs 3: 69-76

Roughgarden J, Gaines S, Possingham H (1988) Recruitment dynamics in complex life cycles. Science 241:1460-1466

Sammarco PW (1991) Geographically specific recruitment and post-settlement mortality as influences on coral communities: the cross-continental shelf transplant experiment. Limnol Oceanogr 36:496-514

SAS Institute (1999) SAS OnlineDoc Version 8, Cary, NC

Sato M (1985) Mortality and growth of juvenile coral Pocillopora damicornis (Linnaeus). Coral Reefs 4:27-33

Shlesinger Y, Loya Y (1991) Larval development and survivorship in the corals Favia favus and Platygyra lamellina. Hydrobiologia 216/217:101-108

Shlesinger Y, Goulet TL, Loya Y (1998) Reproductive patterns of scleractinian corals in the northern Red Sea. Mar Biol 132:691-701

Smith SR (1992) Patterns of coral recruitment and post-settlement mortality on Bermuda's reefs: comparisons to Caribbean and Pacific reefs. Am Zool 32:663-673

Somerfield PJ, Clarke KR (1995) Taxonomic levels, in marine community studies, revisited. Mar Ecol Prog Ser 127: 113-119

Southwood TRE (1966) Ecological methods. Chapman \& Hall, London

Tanner JE, Hughes TP, Connell JH (1996) The role of history in community dynamics: a modelling approach. Ecology 77:108-117

Warwick RM, Clarke KR, Suharsono (1990) A statistical analysis of coral community responses to the 1982-83 El Niño in the Thousand Islands, Indonesia. Coral Reefs 8: 171-179

Wittenberg M, Hunte W (1992) Effects of eutrophication and sedimentation on juvenile corals. 1. Abundance mortality and community structure. Mar Biol 112:131-138

Zakai D, Chadwick-Furman NE (2002) Impacts of intense recreational diving on reef corals at Eilat, northern Red Sea. Biol Conserv 105:179-187

Submitted: October 25, 2005; Accepted: January 25, 2006

Proofs received from author(s): July 11, 2006 